\title{
The Status of the Smithsonian Microbeam Standards
}

\author{
Timothy R. Rose
}

Department of Mineral Sciences, NHB 119, Smithsonian Institution, Washington, D.C. 20560

Over the past thirty years, the Department of Mineral Sciences of the Smithsonian Institution has distributed microbeam reference materials free of charge to laboratories in twenty-nine countries and thirty-five states. Over one thousand requests have been processed totaling over 15,000 samples (see figure 1). Known as the Smithsonian Microbeam Standards (SMS), most of these materials were chosen from our mineral and rock collections. They were characterized by traditional gravimetric analysis, beginning in the 1960's, in the laboratories of the Department of Mineral Sciences, under the supervision of Eugene Jarosewich. A total of thirty-six minerals and glasses were established for use as microprobe "standards" [1,2]. Three of these were further characterized by round-robin analyses by electron microprobe involving USGS and MIT laboratories [3]. More recently, the collection has grown with the donation of rare-earth-element and Y and Sc orthophosphates and seven synthetic glasses $[4,5,6]$.

A thorough reorganization of the SMS collection has been undertaken. This has constituted a complete inventory including updating the existing masses of each material, consolidation of various vials of these materials into single trays, reconciliation of issues with specimen numbers, and the discovery of issues about the origin and condition of some of the samples. In addition we have added logistical staff to help with curation, documentation of requests for disposal and communication with those requesting materials. Data sheets for each reference material are being added to our website. Each data sheet will contain the composition, source of the material, an electron image, an energy-dispersive x-ray spectrum with downloadable .emsa file, notes on grain size fractions available, impurities, inhomogeneity and any other known characteristics of the material and pertinent references to the material. An example data sheet is given in figure 2 . These will be updated as new information, such as trace element data, becomes available.

Requests for SMS are received weekly. In addition to requests for new standard sets, often they are for replacement grains for long-established labs, and for large grains for laser ablation characterization and specialized studies. Large grains of many SMS are not available. A few of the SMS are now in less than one gram quantities. The Smithsonian collections are a logical source of material for replacement of these and creation of new reference materials as needed by the community. The Department of Mineral Sciences no longer maintains a traditional wet chemistry laboratory so these materials will have to be characterized by other methods, likely cooperative inter-laboratory studies.

\section{References}

[1] Jarosewich et al., Geostandards Newsletter, 4, no. 1, 43-47 1980

[2] E. Jarosewich, J. Res. Natl. Inst. Stand. Technol. 107, 681-685 (2002)

[3] Jarosewich et al., Smith. Contr. Earth Sciences, 22, 53-67 (1979)

[4] Jarosewich, E. and L. A. Boatner, Geostandards Newsletter, 15, no.2, 397-399 (1987)

[5] Carpenter et al., J. Res. Natl. Inst. Stand. Technol. 107, 703-718 (2002)

[6] Vicenzi et al., J. Res. Natl. Inst. Stand. Technol. 107, 719-727 (2002) 


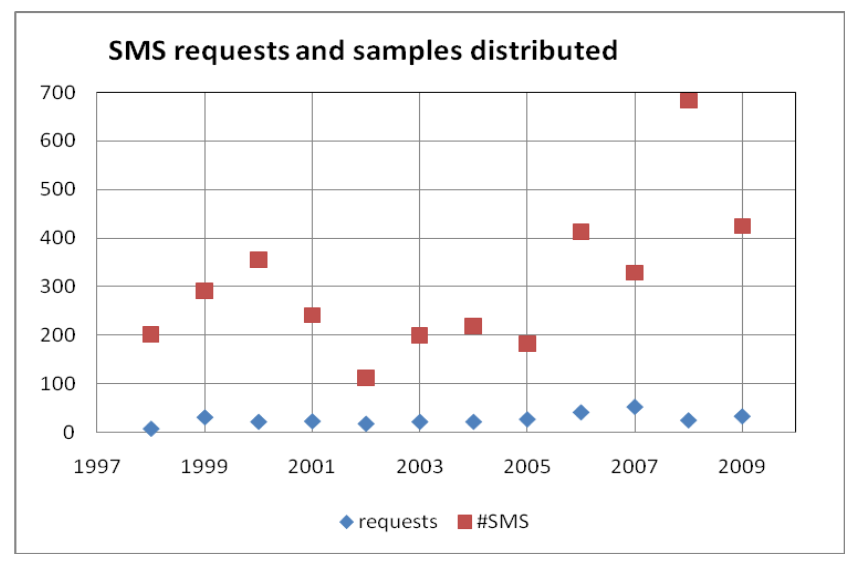

Figure1. SMS requests and samples disposed by year.

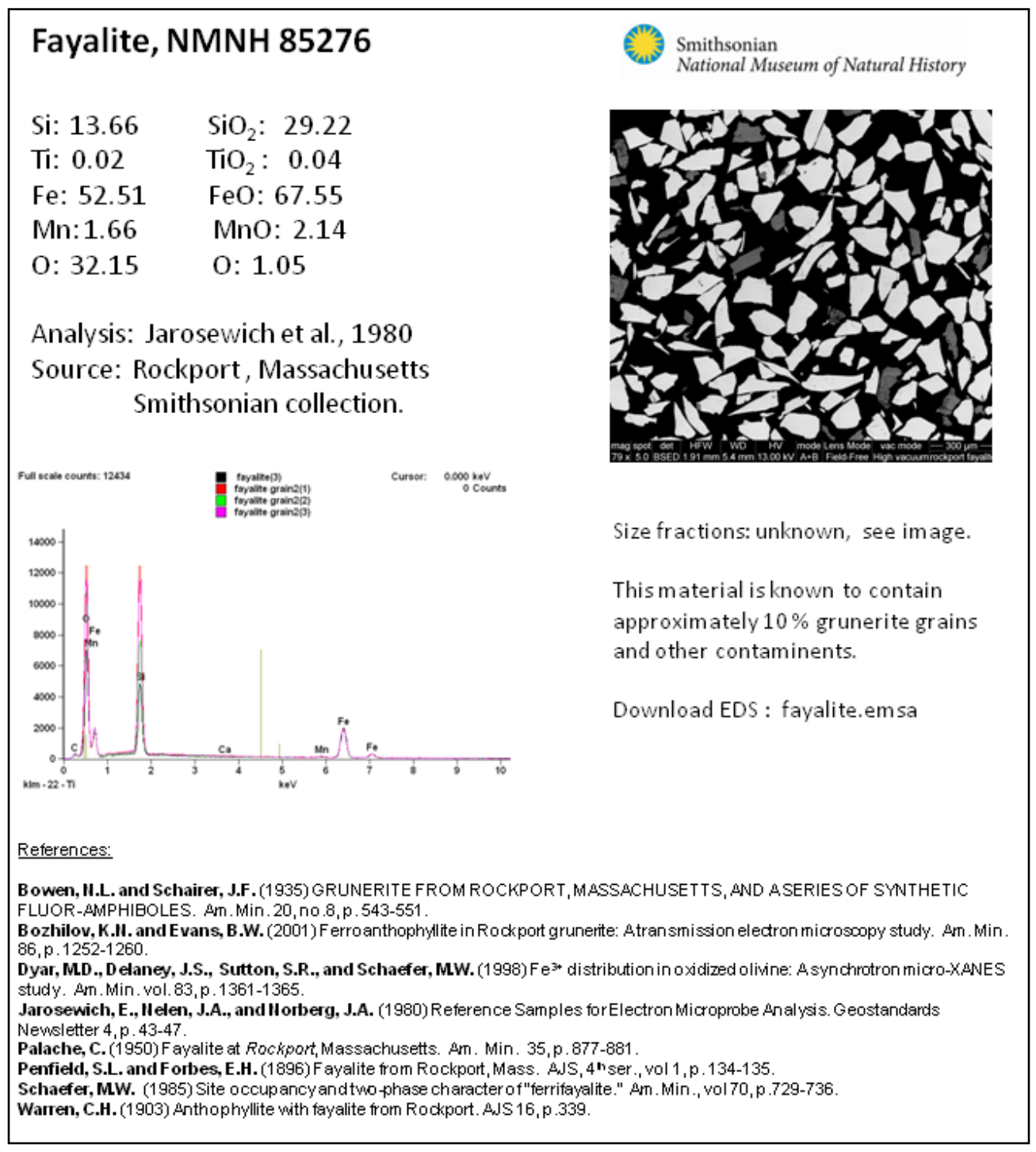

Figure 2. Sample SMS data sheet. 